\title{
Student-Athlete' Sports Confidence and Motivation to Practice: A Basis for Intervention Program in Dealing with Game Outcomes
}

\author{
Shara May T. Espinol, Rpsy, RPm \\ University of Batangas \\ Batangas City, Batangas, Philippines \\ Diane D. Lipat \\ University of Batangas \\ Batangas City, Batangas, Philippines
}

\author{
Daniel Deleniana, LPT \\ University of Batangas \\ Batangas City, Batangas, Philippines \\ Glenn Lacsamana \\ University of Batangas \\ Batangas City, Batangas, Philippines
}

\begin{abstract}
This is a descriptive-comparative study that aimed to measure the student-athletes' motivation to practice and sport confidence before and after winning and losing in major athletic events. The researchers invited 48 athletes from the University of Batangas playing different categories of sports based on their availability. In gathering the data, the researchers used adopted questionnaires after contacting and asking permission from the original authors of the instrument. Results showed that there is a significant difference in the sport confidence of the losing team. There is also a significant difference in the motivation to practice of the losing team in terms of intrinsic motivation, integrated motivation, identified regulation, and introjected regulation. Based on the results, the researchers proposed tips for the Sports Development Office of the University of Batangas to help the student-athletes in properly managing their interpretation of winning and losing in games.
\end{abstract}

Keywords: Sport confidence, motivation to practice, student-athletes, descriptive research

\section{Introduction}

Student-athletes, just like any normal students, also experience psychological disturbances from time to time. In 2010, Senate Bill 1194, known as An Act Providing Magna Carta for Studentathletes, defined these students, as being enrolled in any school and is part of the school athletic team that represents the school in different competitions. The same bill stated the rights of the student-athletes, as well as their responsibilities and the responsibilities of the school. It stated that student-athletes should be provided with counselors aside from expert coaches to help them manage their lives and reach their full potentials. As representatives of the schools in different sporting events, most of them spend their time outside the school for competitions and practices. Every time they win, they need to prepare for the bigger league and when they lose; they have to train harder to win the next game. Not all student-athletes go on with their lives to become professional athletes, but some of them do and can compete at international levels. For most, being student-athletes is a source of financial funding for education, but for some, it could 
be a worthy career in the future. And most people only see these students as athletes and not as student-athletes who experience the same kind of dilemma that other students do because they spend most of their lives playing. It may seem that the lives of the student-athletes revolve around winning or losing the game.

As an educator, who at times has experienced counseling student-athletes, the researcher has encountered different reasons for the drop in motivation to practice as well as sportconfidence. Some student-athletes may feel that they fall short on practicing that is why they lost the game. Because of this, they get an increased motivation to practice. But they are also some who get demotivated. On the other hand, it is common for them to have high sport-confidence whenever they win, which could sometimes make them feel that they do not need to practice at all. These experiences are also evident and reflected in the gathered literature for this study.

This study intends to measure the student-athlete's confidence after winning or losing a game. It also explores the effects of winning and losing on their motivation to practice. In every game, there is always a winner and a loser. Inetwork (2017) stated that winning is not everything and losing does not always mean failure. The article focused on looking at both states differently to improve the performance of the players. According to this article, if the student-athletes could associate losing with positive things, then they will have a better outlook in life and in playing. However, this is not always the case as losing often leads to lower confidence and therefore feelings of demotivation to practice. In the long run, being demotivated to practice leads to poor performance in sports which results in more losses and this cycle could go on until the athlete experiences burn out or drop out of playing.

Sport confidence, based on the definition of Vealey as cited in the article of Beachy (n.d.) in Believe Performance, is defined as an individual's belief in their ability to be successful in playing sports. Confidence is very important, as it has been identified as one factor that could influence athletes' performance in their games. It could be affected by factors including situational favorableness when winning the game and vicarious experiences when watching the team try to win the next game despite losing. Motivation is defined as the force that directs people to move through goal-directed behavior (Cherry, 2018). Therefore, motivation to practice has been defined by the researchers as the desire to practice and engage in sports.

The website of the Positive Psychology Program discussed the motivation theory of Edward L. Deci and Richard M. Ryan about self-determination theory (as cited in Ackerman, 2018). According to the theory, motivation may be intrinsic or extrinsic. It can also be autonomous or controlled. External sources fuel extrinsic motivation and yield external rewards while intrinsic motivation is driven by internal drives. Autonomous motivation is achieved when an individual feels that an activity's value is aligned with their sense of self. Therefore, it could be both from internal or external sources. External and introjected regulation makes up controlled motivation. Both of which makes an individual feel the pressure to behave in a specific way and have very little autonomy.

Self-determination theory grew from the work of Deci and Ryan and it links personality, human motivation, and optimal functioning (as cited in Ackerman, 2018). When applied to sports, it is seen that intrinsic motivation is stronger than extrinsic motivation in attaining goals. Therefore, feelings of winning or losing could greatly affect an individual's motivation to work towards winning. Being confident is also part of intrinsic motivation as well as autonomous motivation. When an athlete values a specific sport and feels confident about their ability to win it, they work harder to achieve what they feel they deserve. Other researches in sports support this theory and show that those who are motivated by external regulation and external standards, 
such as being pressured by the coach to win, are more likely to stop playing. In the study of Calvo, Cervello, Jimenez, and Iglesias (2013), they concluded that adolescent athletes continue to engage in sports due to the satisfaction of autonomy, competence, and relatedness, all of which could be achieved by winning a game and having the confidence to win. Also, dropouts were seen as a result of external factors and lower satisfaction of the three needs.

Inetwork (2017) presents how a different frame of the orientation of winning and losing could change a student-athlete's perspectives. If the game becomes all about winning, the player forgets to enjoy the game and gets a higher level of disappointment if they lose. If losing is seen as a failure, someone who does not win might never try again. If this is true, then only those who win will be motivated to practice, and those who do not will quit. But this is not always the case. This article states that losing could be seen as a challenge; therefore, it would push the player to practice more. But the point remains that winning and losing have different effects on the athletes and this is supported by several articles and researches discussing what happens to the sport-confidence and motivation to practice by the athletes due to the results of a game.

An article in Psychology Today, the author, Wood (2014) explained in his introduction, how winning in sports is associated with pleasure resulting in athletes' feeling of being afraid of losing. This is strengthened by experience whenever players win and lose a game; the pleasure of the fear is repeatedly experienced. This is the reason why some athletes develop a strong motivation to avoid losing by training more and more. But to a greater extent, Wood also states that this could hurt the athletes. He believes that the coach and support staff should do something to properly develop a healthy outlook with regards to winning and losing.

Brown (2016) from the University of Alberta used the experience of Michael Jordan to illustrate how important it is for athletes to have the right frame of orientation when it comes to experiences of winning and losing. In his article, he wrote how in 1997, world-famous brands, Nike used Jordan's losing experiences in their advertisement to highlight how one should not give up even if it meant losing 300 games and missing 9000 shots. This article showed what Wood (2014) explained in his article that due to the fear of losing again, players tend to continue practicing until they succeed.

This notion is supported by several studies including that of Ibrahim, Jaafar, Kassim, and Isa (2016) who studied the motivational climate, self-confidence, and success of student-athletes. The result of their study suggested that self-confidence mediates between motivation and success. If the athletes believe that they can win, they are also more motivated to continue engaging in sports and have higher chances of winning a game. On the other hand, Sari, Ekici, Soyer, and Eskiler (2015) they found out that self-confidence is positively correlated with the different constructs of intrinsic and extrinsic motivation among hockey athletes. Hockey players with higher self-confidence also have higher intrinsic and extrinsic motivation in sports. Vink, Raudsepp, and Kais (2015) find out that the intrinsic motivation and self-confidence of adolescent athletes are reciprocally related to each other. Therefore, self-confidence may act both as a mediator and an independent or dependent variable concerning motivation in sports.

Martins, Honorio, Cardoso, and Duarte (2014) used factor analysis to find out the reasons why their respondents are motivated to practice or participate in school sports. They found out that among the reasons why the students want to practice is because they want to improve their technical capabilities and overcome challenges. The same is found in the study of Mudrak, Slepicka, and Slepickova in 2018 where they found out that winning is related to intrinsic motivation. They also found that intrinsic motivation is negatively related to negative sport attitudes such as doping and cheating. In their literature, Khan, Haider, Ahmad, and Khan 
(2011) discussed how players who won and were able to reach an international level had higher levels of achievement motivation compared to players who did not play in the international games. These studies suggest that athletes are motivated to practice because they want to be better at playing and to continue achieving wins and moving forward in their track as athletes.

It could not be denied that confidence and motivation are always related when it comes to sports. A longitudinal study conducted by Skinner in 2013 suggested that team confidence may be related to the success of the team. There is a slight correlation coefficient between winning and the measure of collective efficacy of the team, which was measured five times across several seasons. Although there was a drop in the performance of the team, when they began winning, their confidence also increased. Losing previous games led the team to get motivated to practice more and therefore to improve their performance. This study also highlights that intrinsic motivation is very important in sports as team spirit fosters the relatedness that is an essential part of motivation according to self-determination theory.

Athletes' source of confidence according to Machida, Ward, and Vealey (2012), include controllable and uncontrollable factors. Controllable sources of confidence such as mastery may be gained through practice while uncontrollable sources include winning or losing. This is why when athletes lose a game, they focus on things that they could control such as practicing more to win the next time. Meanwhile, Rintaugu, Mwangi, and Toriola (2018) found out in their study that sport-confidence comes from several factors including vicarious experiences such as seeing others win or loss, mastery, and demonstration of ability, such as being able to win or lose a game. In addition to this, the coach's leadership also affects the sport confidence of the athletes. Still, it could not be denied that the uncontrollable factors affect individuals very much. Covassin and Pero (2004) studied collegiate tennis players and found that winning resulted in higher confidence and lower total mood disturbance compared to losing players. The athletes who have higher confidence were able to perform properly during the game and were not easily affected by negative outcomes.

With all the gathered literature and studies, it is clear how winning and losing a game could affect the sport-confidence and motivation to the practice of athletes as well as the interpretation of every loss. Understanding and interpreting the results of a game has been highlighted by Inenetwork (2017), Wood (2014), and Brown (2016). Confidence is seen as a dependent or independent variable but it could also well be a mediator variable as mentioned in the study of Ibrahim et.al (2016). Most literature treated it as a dependent variable that is affected whenever athletes lose a game. Motivation as discussed in the self-determination theory and applied in the field of sports by the different studies mentioned above is indeed affected by a lot of factors. Intrinsic motivation remains a strong factor to be considered when trying to motivate athletes as relatedness, feelings of achievement, and autonomy are very important. Extrinsic motivation may be easier to control and more stable than extrinsic motivation but it still affects whether an athlete will practice or not. The literature gathered focused both on professional and student-athletes however, none compared the difference in the levels of sport-confidence and motivation to the practice of student-athletes, thus there is a literature gap that the present study could fill.

This study is important because student-athletes, although they comprise a very small percentage of the student population, are often seen as models and are easily noticeable to others. Focusing on their psychological well-being is very important to make sure that they are not only physically strong but also psychologically healthy. This will make them good models and inspirations for other students. With the help of the school, they can reach their full potentials, both as persons and athletes. This study will also contribute to the growing field of sports 
psychology in the Philippines. Although self-confidence and motivation are highly researched concepts in Psychology, there are very limited related studies and literature about these variables related to student-athletes. This research seeks to help student-athletes by developing a program for debriefing after winning or losing a game. The program may be facilitated by the Sports Office and all the coaches may be trained to conduct the debriefing.

In answering the general aim of this research to understand how winning and losing a game could affect the sport-confidence and motivation to the practice of the student-athletes, the following objectives were used: (1) To measure the student-athletes' sport-confidence before and after winning or losing a major game; (2) To measure the student-athletes' motivation to practice before and after winning or losing a major game; (3) To measure the significant difference between the student-athletes' sport-confidence and motivation to practice before and after winning or losing a game; and (4) To propose an output that could help the student-athletes regulate their motivation to practice and level of sport-confidence. It is then hypothesized that there is no significant difference in the student-athletes' sport-confidence and motivation to practice before and after winning or losing a game. Figure 1 presents the conceptual framework of this research.

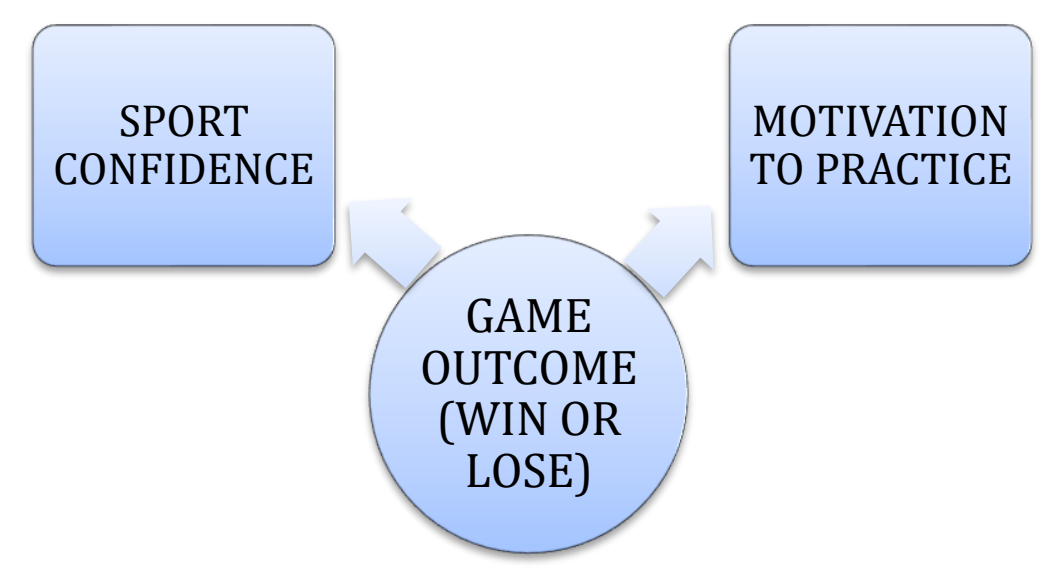

\section{Figure 1. Effects of winning and losing in the sport-confidence and motivation to the practice of student-athletes'}

\section{Method}

\section{Participants}

Student-athletes of the University of Batangas, engaged in all fields, were the participants of this study. They could be playing as individuals or with a team in a category of indoor and outdoor sports for at least one year. The researchers used non-probability convenient sampling for this study due to the availability of the athletes. Due to the systematic bias that this method may bring, the researchers managed to find student-athletes who engage in different sports.

\section{Design}

The researchers used a descriptive-comparative design in this quantitative study. Quantitative research uses inferential statistics to answer the research statements (Hernandez, Buela, 2018). This research design allows the researchers to conclude that one variable is better than the other or has a higher level of measure (Villanueva, 2013). 


\section{Materials}

Two adopted scales were used for this study. The authors contacted the developers of the test and asked their permission to use it. The authors of the original scales promptly replied with their approval along with the details of the psychometric properties of the tests which were established through research and pilot testing. The first instrument is the Sport Motivation ScaleII developed and validated by Luc G. Pelletier, Meredith A. Rocchi, Robert J. Vallerand, Edward L. Deci, and Richard M. Ryan in 2012. It measured both intrinsic and extrinsic motivation of athletes towards sports using a seven-point Likert scale ranging from Does not correspond at all to Corresponds completely. It measures six different types of motivation towards sports including, intrinsic, integrated, identified, introjected, external, and amotivated. The second instrument is the Trait Sport-confidence Inventory developed by Robin Vealey (1986). It is a nine-point Likert scale with answers ranging from Low to High and it measures sport-confidence as a trait rather than a state.

\section{Procedure}

Data gathering was done in the university during the availability of the respondents. The researchers used an Informed Consent in gathering the data for the study. The participants who were willing to provide information for the study were asked to sign the consent form. Privacy and confidentiality were ensured by asking the students to report to an office while answering the instruments. Their names were paired with codes and only the researchers processed the obtained data. There was a minimum risk involved in the study since the participants had to spend 15 to 20 minutes of their time answering the instruments. To address this, the researchers made sure that the respondents answered the instrument in a quiet environment where they are relaxed and it was done after their classes. Another ethical consideration for the study is plagiarism, particularly since the instruments used were developed by foreign authors. This is addressed by contacting the authors and asking for their permission to use the test. No other ethical considerations were encountered in doing the study.

The initial data was gathered at the start of the semester. Then the second gathering of data was done after several major leagues were finished within the school year. The data were then collated and tallied. Descriptive and comparative statistics were used to analyze the data. The gathered data were compared to find a significant difference between self-confidence and motivation to the practice of the student-athletes who won or lost in major games. Specifically, the level of sport-confidence and the motivation to practice were compared before the games and after the games. The results of those who won and lost the games were separated to find out whether it is losing or winning that makes a difference in their confidence and motivation. T-test was the inferential statistical tool used for this purpose.

\section{Results}

The researcher measured the level of sport-confidence and the motivation to practice of the student-athletes and then compared those using inferential statistics.

\section{Descriptive statistics}

To answer the objectives of the study, the researchers gathered data from 48 athletes who were willing to participate in the study. Each athlete who participated in the study had to answer the questionnaires twice; first during the start of the semester, and second, was after they have engaged in several major sports events. The descriptive data are presented in the following tables. 
Table 1. Respondent's Level of Sport Confidence Before and After a Game; $n=48$

\begin{tabular}{llllllllll}
\hline & \multicolumn{3}{c}{ Before (win) } & \multicolumn{2}{c}{ After (win) } & \multicolumn{2}{c}{ Before (lose) } & \multicolumn{2}{c}{ After (lose) } \\
& Mean & Int & Mean & Int & Mean & Int & Mean & Int \\
\hline Confidence & 7.110 & High & 6.813 & High & 6.995 & High & 5.789 & $\begin{array}{l}\text { Mediu } \\
\text { m }\end{array}$ \\
\hline
\end{tabular}

Legend : $1.00-3.49$ (Low), $3.50-6.49$ (Medium), 6.50 - 9.00 (High)

The table above presents the mean for the level of confidence of 48 athletes before and after winning or losing a game. Athletes' level of confidence before win has a mean of 7.110 and 6.813 after the win which indicates that they both have high confidence. While athlete's level of confidence before the loss has a mean of 6.995 which means they have a high level of confidence before losing the game and a mean of 5.789 which shows that athletes' level of confidence fluctuates and they showed a medium level of confidence after losing the game. Although there was a numerical change in the confidence of the athletes who won and lost in the games, there was a bigger drop in the confidence of those who lost the game since the interpretation went from High to Medium. The slight drop in their confidence level after winning the game could be attributed to the length of time between facilitating the measures and the number of academic demands they are managing. Academic requirements tend to damper the happy mood of the student-athletes because despite winning they still have to adhere to the classroom activities.

According to Dr. Goldberg (2019) in his Competitive Advantage Newsletter, selfconfidence is that intangible factor that keeps an athlete working hard regardless of how many times he/she may fail or how many obstacles get thrown in his/her path. Self-confidence can give an average athlete or team the courage and focus to defeat a stronger opponent. Selfconfidence can motivate one to attempt and accomplish the impossible. Likewise, lacking selfconfidence, an athlete or team will consistently perform way below their potential. Low selfconfidence can stop an athlete's enjoyment of the sport and turn him or her into a dropout statistic. Vice versa, winning or losing a game could have an impact on the confidence of the players where winning could increase it, and losing could decrease it, affecting their performance in future games.

\section{Motivation to Practice of Student-Athletes Before and After Winning or Losing a Game}

Table 2. Respondent's Motivation to Practice Before and After a Game; n=48

\begin{tabular}{lllllllllll}
\hline & \multicolumn{2}{c}{ Before (win) } & \multicolumn{2}{c}{ After (win) } & \multicolumn{2}{c}{ Before (lose) } & \multicolumn{2}{c}{ After (lose) } \\
& Mean & Int & Mean & Int & Mean & Int & Mean & Int \\
\hline Intrinsic regulation & 6.523 & CComp & 6.095 & Clot & 6.547 & CComp & 5.381 & CBiyt \\
Integrated regulation & 6.201 & Clot & 5.924 & Clot & 6.048 & Clot & 5.214 & CBit \\
Identified regulation & 6.401 & Clot & 6.066 & Clot & 6.287 & Clot & 5.571 & Clot \\
Introjected regulation & 5.304 & CBit & 5.371 & CBit & 5.286 & CBit & 4.475 & CMod \\
External regulation & 4.457 & CMod & 4.610 & CBit & 3.715 & CMod & 4.022 & CMod \\
Nonregulation & 3.781 & CMod & 4.029 & CMod & 3.405 & CL & 4.357 & CMod
\end{tabular}

Legend: 1.00 - 1.49 (Does not correspond at all, DC), 1.50 - 2.49 (Corresponds very little, CVL), 2.50 - 3.49

(Corresponds a little, CL), 3.50 - 4.49 (Corresponds moderately, CMod), 4.50 - 5.49 (Corresponds quite a bit, CBit), 5.50 - 6.49 (Corresponds quite a lot, Clot), 6.50 - 7.00 (Corresponds Completely, CComp) 
The table above presents the mean for the motivation to practice by the 48 athletes before the win and after the win and before the loss and after the loss of the game. The athlete's motivation before win has a mean of 6.523 as seen in the intrinsic regulation and a mean of 6.095 after the win which indicates that they correspond completely and quite a lot correspondingly. While an athlete's motivation before the loss has a mean of 6.547 , which means they correspond completely, and 5.381 after loss which means they correspond quite a bit. Overall, changes in selected athletes' motivation can be seen after they lost a game.

Student-athletes are young people who are motivated to practice and engage in sports especially when they are winning. The fame and recognition that the sport brings could easily drive them to do better next time so that they can achieve more. However, losing could easily dishearten them to play the game due to shame. On the other hand, wanting to win the next game after a big loss could also motivate them to want to practice more. It shows that winning or losing the game could serve as both internal and external motivators.

According to Hartley (2011), as written in the Podium Sports Journal and is related to the self-determination theory, many athletes find that their motives to engage in sports change over time. They begin playing due to their love for the sport and they enjoy what they are doing. This is purely intrinsic. But as they continue to play, the motivation to play the game and be good at it becomes associated with other things. They begin to enjoy the game due to their teammates and they get challenged by players from other teams. Winning also gives them the joy of being recognized. Great performance leads to more recognition not just from the coach and their teammates but also from people who are watching them play. Their motivation then becomes integrated to the other reasons for playing, introjected with their former motives, identified with the new things that engaging in sport brings, and external as it is increased by external factors.

\section{Inferential Statistics \\ Significant Difference in the Sports Confidence of the Student-Athletes Before and After Winning or Losing a Game}

Table 3. Differences on the Respondent's Level of Sport Confidence Before and After a Game; $\mathrm{n}=48$

\begin{tabular}{llllll} 
& Mean(b) & Mean (after) & $t$ & p-value & Interpretation \\
\hline Confidence (win) & 7.110 & 6.813 & 0.988 & 0.330 & Not Significant \\
Confidence (lose) & 6.995 & 5.789 & 2.840 & 0.015 & Significant \\
\hline
\end{tabular}

Legend: Mean difference is significant at the 0.05 alpha level

The table above presents the difference in respondent's level of confidence before and after a game. The $t$ value obtained has a value of 2.840 which means that there is a significant difference in the confidence level of selected athletes after losing a game but there is no significant difference in the level of confidence for those who won the game. Therefore, among the 48 participants, only student-athletes who lost in the major games experienced a change in their level of confidence. This projects that losing a game changes the sport confidence of student-athletes whereas winning does not. Losing could bring about feelings of shame and lead them to perceive themselves as inadequate when it comes to playing the sport. Some of them may feel that they lost the game because of their poor performance and drive them to focus more on the faults that they have committed during the game. This negativity could further 
result to lower sport-confidence and affect their next performance. The researcher can reject the null hypothesis for the losing group.

In an article in Psychology Today, written by Wood in (2014), it was explained that winning in sports is associated with pleasure resulting in athletes' feeling of being afraid of losing. This is strengthened by experience whenever players win and lose a game. This is why some athletes try to avoid losing by training more and more because losing affects their confidence in playing their sport. But to a greater extent, Wood (2014) also states that this could harm the athletes. Machida and colleagues (2012) summarized in their study how sport confidence is affected by controllable and uncontrollable factors. Winning and losing a game are uncontrollable factors that heavily affect the confidence of players, however, controllable factors such as mastery that is gained through practice are more critical. Uncontrollable factors may also lead to maladaptive perfectionism or putting too much pressure on the self to do better next time.

\section{Significant Difference in the Motivation to Practice of the Student-Athletes Before and After Winning or Losing a Game}

Table 4. Differences on the Respondents' Motivation Before and After a Game; $n=48$

\begin{tabular}{|c|c|c|c|c|c|}
\hline & $\operatorname{Mean}(\mathrm{b})$ & Mean (after) & $\mathrm{t}$ & $\mathrm{p}$-value & Interpretation \\
\hline \multicolumn{6}{|l|}{ Winning Team } \\
\hline Intrinsic regulation & 6.523 & 6.095 & 2.421 & 0.021 & Significant \\
\hline Integrated regulation & 6.201 & 5.924 & 1.552 & 0.130 & Not Significant \\
\hline Identified regulation & 6.401 & 6.066 & 1.761 & 0.087 & Not Significant \\
\hline Introjected regulation & 5.304 & 5.371 & -0.258 & 0.798 & Not Significant \\
\hline External regulation & 4.457 & 4.610 & -0.449 & 0.656 & Not Significant \\
\hline Nonregulation & 3.781 & 4.029 & -0.736 & 0.467 & Not Significant \\
\hline \multicolumn{6}{|l|}{ Losing Team } \\
\hline Intrinsic regulation & 6.547 & 5.381 & 4.269 & 0.001 & Significant \\
\hline Integrated regulation & 6.048 & 5.214 & 2.721 & 0.017 & Significant \\
\hline Identified regulation & 6.287 & 5.571 & 3.382 & 0.005 & Significant \\
\hline Introjected regulation & 5.286 & 4.475 & 2.493 & 0.027 & Significant \\
\hline External regulation & 3.715 & 4.022 & -0.592 & 0.563 & Not Significant \\
\hline Nonregulation & 3.405 & 4.357 & -1.872 & 0.084 & Not Significant \\
\hline
\end{tabular}

Legend: Mean difference is significant at the 0.05 alpha level

Table 4 presents the difference between the motivation of respondents before the win and after a win and before the loss and after the loss of the 48 student-athlete participants. Results obtained a significant difference in intrinsic regulation which has a $t$ value of 4.269, integrated regulation with a $t$ value of 2.721 , identified regulation with a $t$ value of 3.382 , and introjected regulation with a $\mathrm{t}$ value of 2.493 . The results gathered showed that the motivation 
significantly changes once the respondents lose the competition that they joined. The studentathletes seem to be demotivated by losing the game but their external regulation was not affected. The motivation to practice went down after losing a game, reflecting that it resulted to demotivation. The student-athletes tend to perceive that practicing did not help in winning the game. The researcher is then able to reject the null hypothesis.

This drop-in four aspects of motivation could be because of the drop in sport confidence as well. Feeling inadequate could make them feel that practicing would not help them as all and would not improve their performance. Ibrahim and colleagues (2016) found out that confidence is a mediator between motivation and winning. Winning results to higher confidence and therefore, also leads the athletes to get motivated to continue doing better. On the other hand, lower confidence experienced by losing could lead to demotivation. This is aligned with the study of Khan and co-researchers (2011) where they stated that anxiety, which may be gained from losing a game, has a negative relationship with motivation. When it comes to engaging and practicing sports higher levels of anxiety lead to lower levels of motivation.

\section{Proposed tips for the Sports Development Office}

With the results gathered by the researchers from 48 student-athletes of the University of Batangas, it was found that there is a need to develop an output that could help the studentathletes who participated in the study in staying motivated to practice sports and also to maintain their confidence. After analyzing the results, the researchers formulated the program which may be used by the team coaches and by the Sports Development Office:

\section{BUSY Program for Student-Athletes \\ Build a positive atmosphere}

Teaching athletes how to accept losses properly could help them learn that winning is not the most important thing in playing. This attitude should start from the minute they train so that they could apply it whenever they are in the actual game. Practice should not be imposed as a way to win; rather it should be introduced as a way to be better. Point out opportunities for improvement instead of focusing on their flaws. A simple exercise or routine may be applied after each game to process the emotions of the players regarding the game.

\section{Utilize the value of vicarious experiences}

Allow the athletes not only to practice playing sports with each other but also to watch how each other play. This will give those opportunities to learn from other players in the team which could motivate them or give them an idea of how to improve themselves. They could critic each other as a form of brainstorming. This could be incorporated at the end of every training session.

\section{Show leadership}

Coaches and the sports development office should show leadership by making sure they are also properly motivated and that they are confident in the abilities of the student-athletes. They should also show positivity in all their actions and their reactions to the results of the games. As leaders, they should be the first persons who will provide social support to the athletes whenever they experience losses and they should also be the ones who will remind them of the value of practice when they are being overconfident.

\section{Yield motivation based on motivational cues}

Despite having a passion for the same sports, student-athletes are still individuals and, therefore, they have different personalities. The way to motivate them will vary whether internally or externally. These things should be considered when planning how to motivate 
student-athletes. Careful observation and proper interaction with the student-athletes could help coaches and the sport's development office to determine the motivation of the players. They may also be assisted by the guidance office in determining personality and motivational types.

Table 5. Proposed Plan of Activities

\begin{tabular}{|c|c|c|}
\hline Activity & Objective/s & Target Date \\
\hline \multicolumn{3}{|l|}{ Build a positive atmosphere } \\
\hline $\begin{array}{l}\text { Personality Development } \\
\text { Program using Sports and } \\
\text { Positive Psychology }\end{array}$ & $\begin{array}{l}\text { - To use sports and positive } \\
\text { psychology in helping the } \\
\text { students to properly } \\
\text { approach and interpret } \\
\text { the outcome of their } \\
\text { games } \\
\text { - To instill the value of } \\
\text { purposefulness, } \\
\text { cooperation, } \\
\text { commitment, } \\
\text { determinism, and } \\
\text { confidence }\end{array}$ & $\begin{array}{l}\text { - After every major game, } \\
\text { particularly after losing a } \\
\text { game }\end{array}$ \\
\hline \multicolumn{3}{|c|}{ Utilize the value of vicarious experiences } \\
\hline $\begin{array}{l}\text { Critiquing: I got You, You } \\
\text { got Me }\end{array}$ & $\begin{array}{l}\text { - To use vicarious } \\
\text { experiences as a learning } \\
\text { tool in improving one's } \\
\text { game and attitude towards } \\
\text { a game } \\
\text { - To learn how to accept } \\
\text { criticisms with grace and } \\
\text { learn from other's } \\
\text { mistakes }\end{array}$ & - At least one per semester \\
\hline \multicolumn{3}{|l|}{ Show leadership } \\
\hline $\begin{array}{l}\text { Leadership Training and } \\
\text { Consultation }\end{array}$ & $\begin{array}{l}\text { - To enhance leader- } \\
\text { subordinate professional } \\
\text { relationship } \\
\text { - To help the coaches to } \\
\text { identify the problems and } \\
\text { issues of every athlete } \\
\text { - To help the student- } \\
\text { athletes to gain leadership } \\
\text { insights from their } \\
\text { coaches }\end{array}$ & - At least one per semester \\
\hline \multicolumn{3}{|c|}{ Yield motivation based on motivational cues } \\
\hline $\begin{array}{l}\text { Personality Development } \\
\text { and Orientation }\end{array}$ & $\begin{array}{l}\text { - To take a personality test } \\
\text { that will identify } \\
\text { motivational cues of the } \\
\text { student-athletes } \\
\text { - To learn how to motivate } \\
\text { student-athletes based on } \\
\text { motivational cues }\end{array}$ & $\begin{array}{l}\text { - At the beginning of the } \\
\text { Academic Year }\end{array}$ \\
\hline
\end{tabular}




\section{Conclusion}

Based on the results of the study, the researcher has come to a conclusion that (1) proper interpretation of losing a game must be introduced to the players to avoid lowered sportconfidence, (2) other motivational strategies must be explored and used to motivate the students who lost games to continue practicing, (3) a program must be developed and used to aid the student-athletes whose sport-confidence and motivation to practice were affected after losing a game, and (4) formulation of modules or programs based on sports psychology and the result of the study by the researchers may be done to better guide both athletes and coaches. The module should contain a program for developing the right motivation and sport confidence among student-athletes.

Using the results of the study, a program and proposed plan of activities have been developed to be used by the university. The same program and plan may be used as a basis for developing plans in other universities. Future researches may also approach the same topic in conducting a qualitative study to better explore the needs of student-athletes. A longitudinal measure of sport-confidence and motivation to practice may also be done to cover other variables including experience.

This study is conducted in one of the universities in Batangas City and therefore this is highly applicable to the university under study and the student-athletes who engage in team sports. The measure of sport-confidence and motivation to practice was measured twice only a couple of months apart quantitatively.

\section{References}

Ackerman, C. (2018). What is the self-determination theory of motivation?. Positive Psychology Program. Retrieved from https://bit.ly/2KWIMUT

Beachy, E. (n.d.). Building sports confidence. Believe Performance. Retrieved from https://believeperform.com/building-sport-confidence/

Brown, M. (2016). Research shows that athletes who accept loss are best prepared to win. Retrieved from https://bit.ly/2IxHhYM

Calvo., T. G., Cervello, E., Jimenez, R., \& Iglesias, D. (2013). Using self-determination theory to explain sport persistence and dropout in adolescent athletes. Spanish Journal of Psychology, 13(2). Retrieved from https://doi.org/10.1017/S1138741600002341

Cherry, K. (2018). Motivation: psychological factors that guide behavior. Very Well Mind. Retrieved from https://bit.ly/2qZud6O

Covassin, T., \& Pero, S. (2004). The relationship between self-confidence, mood state, and anxiety among collegiate tennis players. Journal of Sport Behavior (2004), 27(3), 230-242. Chart. Retrieved from https://bit.ly/2IRjBiz

Goldberg, A. (2019). Self-confidence. Competitive Advantage. Retrieved from https://bit.ly/2tejRCG.

Hartley, S. (2011). Motivation in sports - discovering your "Reason". Retrieved from https://bit.ly/2XJxt4k

Hernandez, R. A., \& Buela, A. E. (2018). Practical research 2: a guide in writing a quantitative research. Books Atbp. Publishing Corp., Mandaluyong City.

Ibrahim, H., \& Jaafar, A., Kassim, M., \& Isa, A. (2016). Motivational climate, self-confidence, and perceived success among student-athletes. Procedia Economics and Finance. 35, 503-508. Retrieved from https://bit.ly/2WC6nuy

Inetwork. (2017). Youth sports. The psychology of winning and losing. League Network. Retrieved from https://bit.ly/31tYPOl

Khan, Z., Haider, Z., Ahmad, N., \& Khan, S. (2011). Sports achievement motivation and sports competition anxiety: a relationship study. Journal of Education and Practice, 2(4). Retrieved from https://bit.ly/2WDLsHy 
Machida, M., Ward, R. M., \& Vealey, R. S. (2012). Predictors of sources of self-confidence in collegiate athletes. International Journal of Sport and Exercise Psychology, 10(3). Retrieved from https:// bit.ly/2KgWReY

Martins, J., Honorio, S., Cardoso, J., \& Duarte, L. (2014). Students' motivation to practice sports in school between 9 to 14 years of basic education. Journal of Physical Education and Sports, 14(4), 459470 (2014). Retrieved from https://bit.ly/2Ig9Hbb

Mudrak, J., Slepicka, P., \& Slepickova, I. (2018). Sports motivation and doping in adolescent athletes. PLoS ONE 13(10), e0205222. Retrieved from https://doi.org/10.1371/journal.pone.0205222

Pelletier, L., Rocchi, M., Vallerand, R., Deci, E., \& Ryan, R. (2012). Validation of the revised sport motivation scale. Psychology of Sport and Exercise, 14, 329-341. Retrieved from https://bit.ly/2IBqZ1c

Rintaugu, E., Mwangi, F., \& Toriola, A. (2018). Sources of sports confidence and contextual factors among university athletes. Retrieved from https://bit.ly/2KhbMG2

Sari, A., Ekici, S., Soyer, F., \& Eskiler, E. (2015). Does self-confidence link to motivation? A study in field hockey athletes. J. Hum. Sports Exerc., 10(1), 24-35. Retrieved from https://bit.ly/2Ier5wY

Seventeenth Congress of the Republic of the Philippines. (2010). Senate Bill 1194. An Act Providing for the Magna Carta of Student-Athletes. Retrieved from https:// bit.ly/2XHOzzz

Skinner, B. R. (2013). The relationship between confidence and performance throughout a competitive season. Retrieved from https://bit.ly/2X3UGRV

Vealey, R. S. (1986). Conceptualization of sport-confidence and competitive orientation: Preliminary investigation and instrument development. Journal of Sport Psychology, 1986, 8, 221-246.

Villanueva, J. (2013). Types of Descriptive Research. Retrieved from: https://www.slideshare.net/jeanniferbvillanueva/types-of-descriptive-research

Vink K., Raudsepp, L., \& Kais, K. (2015). Intrinsic motivation and individual deliberate practice are reciprocally related: evidence from longitudinal study of adolescent team sport athletes. Psychology of Sport and Exercise, 16(3), 1-6. Retrieved from https://bit.ly/2ZkHa9V

Wood, W. (2014). Maintaining a "Winning” Focus Is Not the Way to Win. There's a paradox at the heart of winning. Retrieved from https://bit.ly/2Zql5qG 


\section{Appendix 1}

Communication with the original authors of the instruments
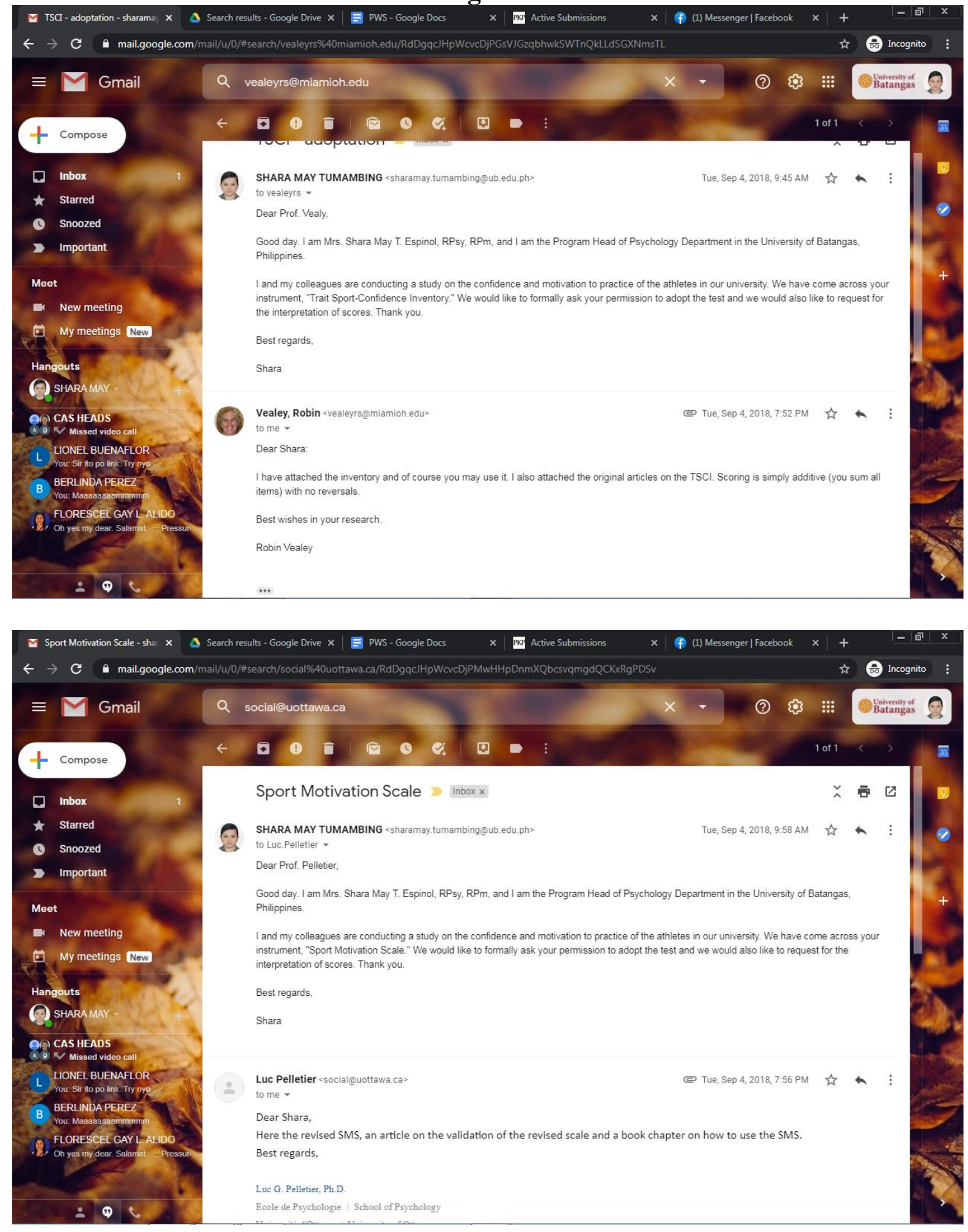

\section{Appendix 2}




\section{Why do you practice your sport?}

Please think about why your practice your primary sport and respond to the questions below. Using the following scale, please indicate to what extent each of the following items corresponds to one of the reasons for which you are presently practicing your sport.

\begin{tabular}{|c|c|c|c|c|c|c|}
\hline $\begin{array}{c}\text { Does not } \\
\text { correspon } \\
\text { d at all } \\
\mathbf{l}\end{array}$ & $\begin{array}{c}\text { Correspond } \\
\text { s very little }\end{array}$ & $\begin{array}{c}\text { Correspond } \\
\text { s a little }\end{array}$ & $\begin{array}{c}\text { Correspond } \\
\text { s } \\
\text { moderately }\end{array}$ & $\begin{array}{c}\text { Correspond } \\
\text { s quite a bit }\end{array}$ & $\begin{array}{c}\text { Correspond } \\
\text { s } \\
\text { quite a lot }\end{array}$ & $\begin{array}{c}\text { Correspond } \\
\text { s completely }\end{array}$ \\
\hline
\end{tabular}

1. Because I would feel bad about myself if I did not take the $\quad \begin{array}{lllllll}1 & 2 & 3 & 4 & 5 & 6 & 7\end{array}$ time to do it.

2. I used to have good reasons for doing sports, $\quad \begin{array}{lllllll}1 & 2 & 3 & 4 & 5 & 6 & 7\end{array}$ but now I am asking myself if I should continue.

3. Because it is very interesting to learn how I can improve. $\quad \begin{array}{lllllll}1 & 2 & 3 & 4 & 5 & 6 & 7\end{array}$

4. Because practicing sports reflects the essence $\quad \begin{array}{lllllll}1 & 2 & 3 & 4 & 5 & 6 & 7\end{array}$ of whom I am.

5. Because people I care about would be upset with me if I $\quad \begin{array}{lllllll}1 & 2 & 3 & 4 & 5 & 6 & 7\end{array}$ didn't.

6. Because I found it is a good way to develop aspects of $\quad \begin{array}{lllllll}1 & 2 & 3 & 4 & 5 & 6 & 7\end{array}$ myself that I value.

7. Because I would not feel worthwhile if I did not. $\quad \begin{array}{lllllll}1 & 2 & 3 & 4 & 5 & 6 & 7\end{array}$

8. Because I think others would disapprove of me if I did not. $\quad \begin{array}{lllllll}1 & 2 & 3 & 4 & 5 & 6 & 7\end{array}$

9. Because I find it enjoyable to discover new performance $\quad \begin{array}{llllllll}1 & 2 & 3 & 4 & 5 & 6 & 7\end{array}$ strategies.

10. I don' t know anymore; I have the impression $\quad \begin{array}{lllllll}1 & 2 & 3 & 4 & 5 & 6 & 7\end{array}$ that I am incapable of succeeding in this sport.

11. Because participating in sport is an integral $\quad \begin{array}{lllllll}1 & 2 & 3 & 4 & 5 & 6 & 7\end{array}$ part of my life.

12. Because $I$ have chosen this sport as a way to develop myself. $\begin{array}{lllllll}1 & 2 & 3 & 4 & 5 & 6 & 7\end{array}$

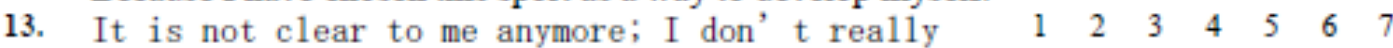
think my place is in sport.

14. Because through sport, I am living in line with $\begin{array}{lllllll}1 & 2 & 3 & 4 & 5 & 6 & 7\end{array}$ my deepest principles.

15. Because people around me reward me when I do. $\quad \begin{array}{lllllll}1 & 2 & 3 & 4 & 5 & 6 & 7\end{array}$

16. Because I feel better about myself when I do. $\quad \begin{array}{lllllll}1 & 2 & 3 & 4 & 5 & 6 & 7\end{array}$

17. Because it gives me pleasure to learn more about my sport. $\quad \begin{array}{lllllll}1 & 2 & 3 & 4 & 5 & 6 & 7\end{array}$

18. Because it is one of the best ways I have chosen $\begin{array}{lllllll}1 & 2 & 3 & 4 & 5 & 6 & 7\end{array}$ to develop other aspects of myself. 
Think about how self-confident you are when you compete in sport.

Answer the questions below based on how confident you generally feel when you compete in your sport. Compare your self-confidence to the most self-confident athlete you know.

Please answer as you really feel, not how you would like to feel. Your answers will be kept completely confidential.

WHEN YOU COMPETE, HOW CONFIDENT DO YOU GENERALLY FEEL? (circle number)

1. Compare your confidence in YOUR ABILITY TO EXECUTE THE SKILLS Low High NECESSARY TO BE SUCCESSFUL to the most confident athlete you $\begin{array}{llllllllll}1 & 2 & 3 & 4 & 5 & 6 & 7 & 8 & 9\end{array}$ know.

2. Compare your confidence in YOUR ABILITY TO MAKE CRITICAL DECISIONS DURING COMPETITION to the most confident athlete

3. Compare your confidence in YOUR ABILITY TO PERFORM UNDER PRESSURE to the most confident athlete you know.

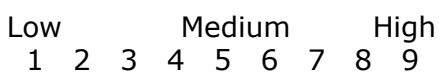

4. Compare your confidence in YOUR ABILITY TO EXECUTE SUCCESSFUL STRATEGY to the most confident athlete you know.

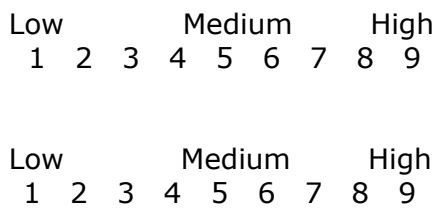

5. Compare your confidence in YOUR ABILITY TO CONCENTRATE WELL ENOUGH TO BE SUCCESSFUL to the most confident athlete you know.

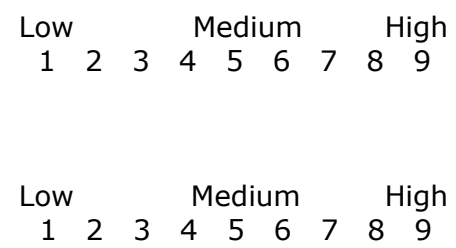

\begin{tabular}{ccccccccc} 
Low & \multicolumn{1}{c}{ Medium } & & High \\
1 & 2 & 3 & 4 & 5 & 6 & 7 & 8 & 9
\end{tabular}

6. Compare your confidence in YOUR ABILITY TO ADAPT TO DIFFERENT GAME SITUATIONS AND STILL BE SUCCESSFUL to the most confident athlete you know.

7. Compare your confidence in YOUR ABILITY TO ACHIEVE YOUR COMPETITIVE GOALS to the most confident athlete you know.

8. Compare your confidence in YOUR ABILITY TO BE SUCCESSFUL to the most confidential athlete you know.

9. Compare your confidence in YOUR ABILITY TO CONSISTENTLY BE SUCCESSFUL to the most confident athlete you know.

10. Compare your confidence in YOUR ABILITY TO THINK AND RESPOND SUCCESSFULLY DURING COMPETITION to the most confident athlete you know.

11. Compare your confidence in YOUR ABILITY TO MEET THE CHALLENGE OF COMPETITION to the most competition athlete you know.

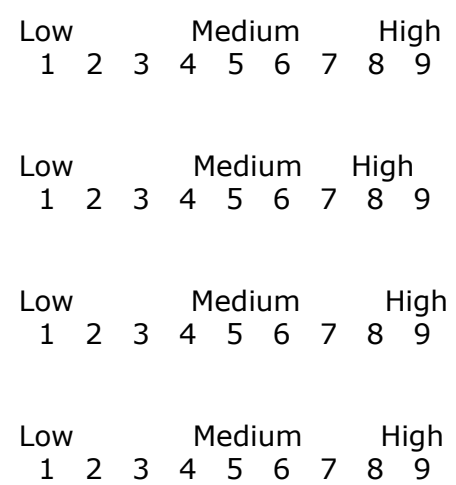

12. Compare your confidence in YOUR ABILITY TO BE SUCCESSFUL EVEN WHEN THE ODDS ARE AGAINST YOU to the most confident athlete you know.

13. Compare your confidence in YOUR ABILITY TO BOUNCE BACK FROM PERFORMING POORLY AND BE SUCCESSFUL to the most confident athlete you know. 